\title{
Mechanical Behavior of Concrete Pavement considering Void beneath Slabs and Joints LTE
}

\author{
Bangyi Liu, ${ }^{1}$ Yang Zhou, ${ }^{2}$ Linhao Gu, ${ }^{1}$ Dalin Wang, ${ }^{1}$ and Xiaoming Huang $\mathbb{D}^{1}$ \\ ${ }^{1}$ School of Transportation, Southeast University, Nanjing 211189, China \\ ${ }^{2}$ School of Materials Science and Engineering, Southeast University, Nanjing 211189, China \\ Correspondence should be addressed to Xiaoming Huang; huangxm@seu.edu.cn
}

Received 30 June 2020; Revised 2 November 2020; Accepted 15 November 2020; Published 24 November 2020

Academic Editor: Linglin Li

Copyright (c) 2020 Bangyi Liu et al. This is an open access article distributed under the Creative Commons Attribution License, which permits unrestricted use, distribution, and reproduction in any medium, provided the original work is properly cited.

Dowel bars are arranged between two slabs of jointed plain concrete pavements to transfer load between them. The looseness of these dowel bars leads to the decrease of the load transfer efficiency (LTE). Meanwhile, repeated vehicle load can result in void near the joints. In this paper, the behaviors of concrete pavement under the effect of void size and joint stiffness were studied by using ABAQUS software. The FEA model was calibrated for different element parameters based on mesh convergence analysis and validated by comparison with previous studies. The voids beneath slabs were considered in this study, including the loaded slab and unloaded slab. The different effects of base course modulus on the stress of loaded slab are also analysed. It is concluded that the results show that the void size and joint stiffness affect the stress of the loaded plate. Smaller void size and larger joint stiffness will lead to the maximum stress located at the bottom of the loaded slab, and the void size has little effect on the stress of the loaded slab. Otherwise, the larger void size will cause larger stress. The effect of base modulus on stress is similar.

\section{Introduction}

Pavement surfaces are frequently built by asphalt because of its lower initial cost; however, concrete pavements are used in roads subjected to heavy traffic loading due to their high compressive strength ability and durability [1]. Jointed plain concrete pavement (JPCP) is generally considered as a multilayer system, in which the concrete slab is directly supported on a treated base course layer or fully compacted subgrade soil. Dowel bars are usually installed at transverse and longitudinal joints of the jointed plain concrete pavement as a result of their structural capacity of load transfer between adjacent concrete slabs [2]. A half of a dowel bar is coated to allow the horizontal joint movement caused by thermal expansion and contraction [3]. In addition, dowel bars are necessary to reduce vertical movements on slab edges and maintain the vertical and horizontal alignment of slabs.

Thin plate theory is widely used to analyse the concrete pavement instead of elastic layer theory because the concrete slab is much stiffer than the asphalt surface [4]. In this theory, it is assumed that the foundation (base course or subgrade soil) is consistently uniform so that the concrete slab is uniformly supported. This assumption can simplify the mechanical analysis of pavement response, yet it is only reasonable in the early stage of pavement life. In fact, many studies have found that there are voids beneath the concrete slabs [5-7]. The occurrence of voids can result in high stress ratio (i.e., the ratio of actual tensile stress to the tensile strength of concrete), which is the major cause of the concrete pavement failure [8].

Numerous studies have previously been conducted related to the causes of the void underneath concrete slabs $[9,10]$. Uneven compaction in the process of subgrade construction will result in uneven subgrade support, which is detrimental to the durability of pavement. The erosion of pumping on the base course or subgrade material cannot be ignored. Rainwater penetrating into the foundation through joints is pumped out when concrete slabs deform under the pressure of vehicle loads [11]. Aggregate particles can be flown away by the contribution of rainwater [12]. Repeated traffic loads will cause soil consolidation in the subgrade and 
plastic cumulative deformation in the base, which can reduce the volume of the foundation material and eventually lead to the void underneath slabs $[13,14]$.

The first systematic calculation of the concrete pavement stress was performed by Westergaard. The closed-form equations were developed based on several restrictive assumptions to calculate displacement and stress of the slab under loading at the edge, interior, and corner [15]. The solution equation method is replaced by numerical simulation methods in the analysis of rigid pavement due to its failing to consider complex loads and arbitrary geometries [16-19]. Three-dimensional (3D) finite element analysis (FEA) has attracted the attention of pavement engineers. Several general-purpose finite element packages are used as a result of their powerful ability to handle complex problems, such as ABAQUS and ANSYS [20-24]. Nevertheless, the FEA model can be difficult to generate effectively and extract results of interest. Many special-purpose software packages were developed for concrete pavement to reduce the difficulty of model analysis, such as KENSLABS [25], EverFE [26], and ISLAB2000 [27]. On the other hand, the limitations of these software are generated due to their specific settings.

The vehicle load is transferred between the transverse joints of the concrete pavement by the dowel bars through the shear force. When vehicle load is applied to one slab, the slab and the adjacent slab are deflected together through the dowel bars. The contact face between the dowel bars and surrounding concrete will be crushed due to high bearing stress caused by repeated vehicle load [28]. Voids will occur in the contact interface between the concrete and the dowel bars, which can lead to the looseness of the dowel bars and the decrease of the load transfer efficiency (LTE). The experimental work reported by Guo et al. noted that dowel looseness (DL) generated by incomplete contact between the concrete and dowel bars inside has a significant impact on critical stresses, maximum deflection, LTE, and pavement deterioration rates [29]. Grosek et al. [30] studied the effectiveness of dowels in concrete pavement by field observation and FE model through SCIA and ANSYS software and concluded that the FEA software can be used for designing and assessment of concrete pavements. Kim et al. [19] examined effect of dowel bar arrangements on performance of JPCP and reported that special dowel bar arrangement could provide similar performance by significant cost savings without any negative effects on expected pavement performance. Mackiewicz [31] presented an FE model of JPCP using commercial software ABAQUS and considered the effect of different diameters and spacing of dowel bars on the slab stress.

It can be observed that most studies on JPCP are based on the assumption that the slab was fully supported by the base course or subgrade. Few studies have focused on the effect of void beneath slabs and DL on slab stress. In particular, few studies considered the effect of void underneath the unloaded slab on the stress of the loaded slab. This study aims to develop an FEA model in ABAQUS, which can accurately simulate the behavior of JPCP with void and DL. The reliability of the model was validated by mesh convergence analysis and comparison with the calculation results of the design standards in China and previous studies. Different size of void beneath the loaded and unloaded slabs and modulus of dowel support are analysed in the validated FEA model with two concrete slabs. In addition, the modulus of base course is also considered in the model. Supercomputing resources are used to reduce the burden of large-sized problem.

\section{Finite Element Modelling}

2.1. General Methodology. Commercial software ABAQUS Standard 6.14 was used in the numerical simulations of JPCP, which corresponded to a selected motorway pavement in China.

The model consists of two structural layers: one is concrete surface course layer, and the other is cement and fly-ash stabilized macadam base course layer. The underlying layers in JPCP have been modelled employing the Winkler foundation. Although spring elements of type SPRING1 were used to idealize the subgrade in a few studies [32], interaction of type elastic foundation is used in this study [33].

Two concrete slabs were established in the surface course of the pavement, which considered the effect of dowel bars. The length and width of the base course layer are usually larger than those of the surface course layer. An extended base was indicated to effectively decrease the stress of slab [34]. Previous studies reported that rational results can be obtained by using linear elastic constitution in the model [31]. The size and material properties of the FEA model are presented in Table 1.

Meshing is a first-order-considerable question in FEA model because of accuracy. Finer mesh can produce better results while leading to excessive computational cost. The finite element type and size were selected by the mesh convergence study in Section 2.3. Eight-node linear hexahedra elements were used for concrete slabs with incompatible modes (C3D8I) and base course with reduced integration (C3D8R). The meshing FEA model of concrete pavement structure is shown in Figure 1.

Hard contact, which is available in the ABAQUS library, was applied to define the interaction between base course and concrete slabs. In order to obtain the most unfavourable stress values in the slab, the relative slide between the concrete slab and the base course layer was considered smooth [35]. The shape of vehicle loads applied to the slab was changed to be rectangular with the same area. The vehicle loads were set at the corner of slabs to consider the most unfavourable cases, as shown in Figure 2. A single-axle load was used to analyse the combined effects of void and DL. A boundary condition of the fixed placement in the horizontal direction is applied to the base course. All displacements at nodes on every side face of concrete slabs are free [36].

The transverse dowel bars were designed as a group of shear spring elements (SPRING2) connecting the specified nodes of the slab to the adjacent slab. The detailed process for this simulation method was proposed by Zhou in his dissertation [37]. In this paper, $q$ represents the normal joint 
TABLE 1: The size and material properties of the FEA model.

\begin{tabular}{lcc}
\hline & Layer properties & Values \\
\hline & Slab length & $4 \mathrm{~m}$ \\
Cement concrete layer (single slab) & Slab width & $3 \mathrm{~m}$ \\
& Slab thickness & $28 \mathrm{~cm}$ \\
& Elastic modulus & $30000 \mathrm{MPa}$ \\
& Poisson's ratio & $10 \mathrm{~m}$ \\
Cement and fly-ash stabilized macadam base course layer & Base length & $5 \mathrm{~m}$ \\
& Base width & $18 \mathrm{~cm}$ \\
Subgrade & Base thickness & $10000 \mathrm{MPa}$ \\
\hline
\end{tabular}

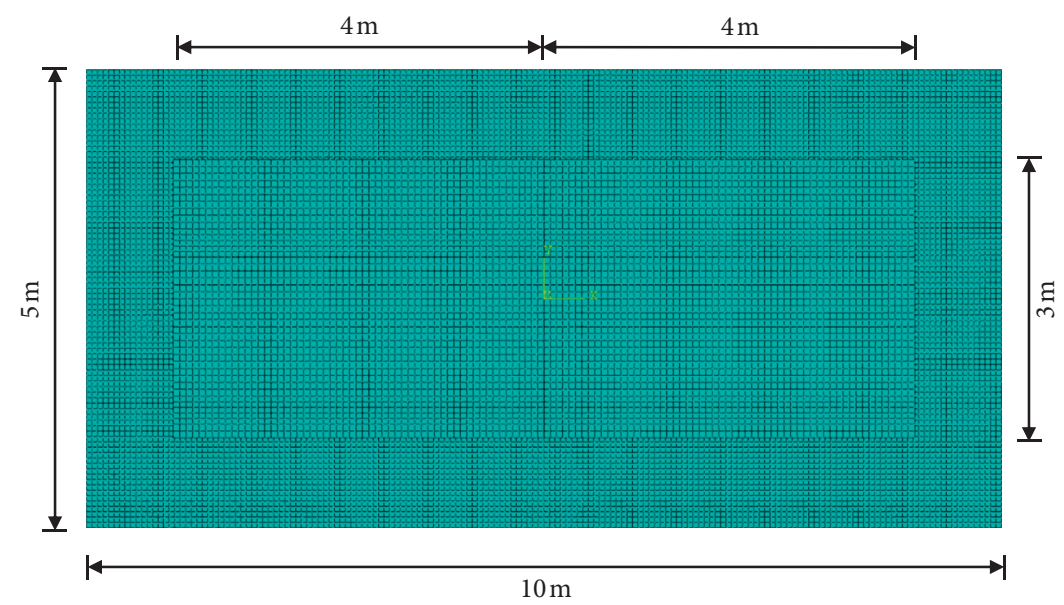

(a)

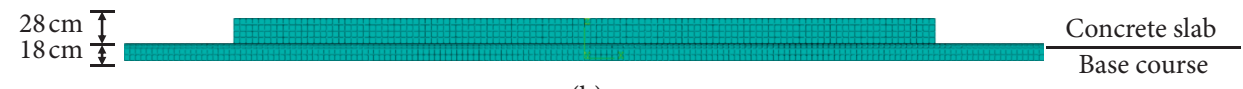

(b)

Figure 1: The FEA model of concrete pavement structure: (a) plane size of the model and (b) vertical size of the model.

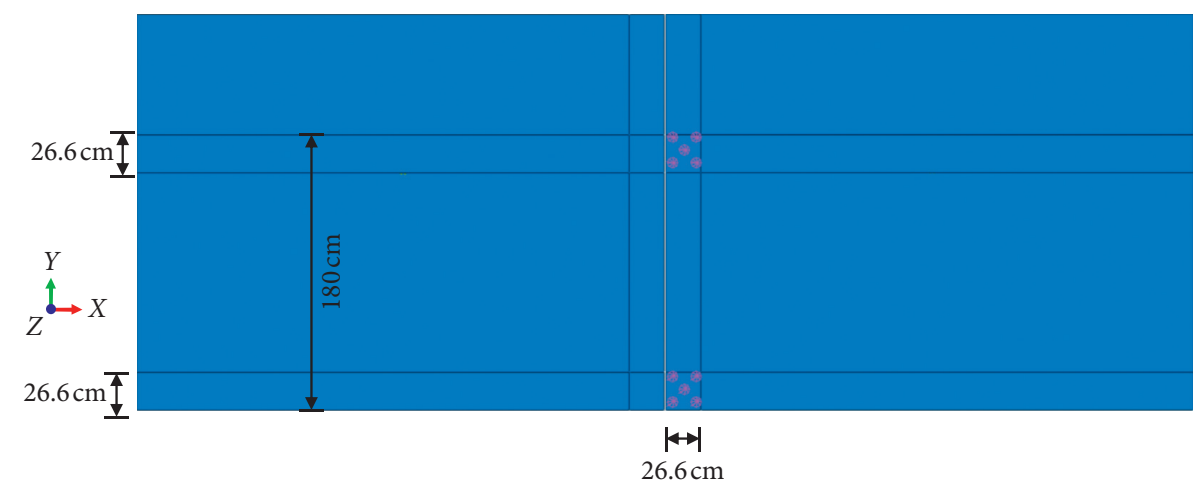

Figure 2: The shape and position of the vehicle load on the slab of FEA model.

stiffness without looseness. The looseness and reinforcement of dowel bars were described by changing $q$, such as $0.01 \mathrm{q}$, $0.1 \mathrm{q}$, and $10 \mathrm{q}$.
2.2. Void Morphology for Simulation. It is reported that the horizontal morphology of the void is square at the edge of the slab and triangle or semicircle at the corner of the slab in 
general [38]. Void underneath the corner of the slab was set to isosceles right triangle to study the load transfer ability. In addition, void beneath the unloaded slab was taken into account, which has not been studied in previous researches. Figure 3 shows difficult shapes of the void underneath the loaded and unloaded slabs.

2.3. Validation of Numerical Models. The convergence owing to element types and mesh size was analysed. C3D8R element has been commonly adopted due to its less computational cost. But the mesh needs to be extremely finely divided to get the accurate result, which is often not easy. In order to overcoming the shortcoming, many researches used 20-node quadratic element (C3D20 or C3D20R) [39] and 27-node quadratic element (C3D27 or C3D27R) [32] in their studies. However, 20-node quadratic element should not be used in the analysis of contact problems, which is suitable for concrete slab on Winkler foundation. It is very costly and complex to rewrite INP file in the analysis using 27-node quadratic element. Incompatible element was used in few studies. In addition, coarse mesh sizes can result in a result that has a significant divergence from accurate result. Nevertheless, finer mesh sizes will increase considerable cost and time of analysis, which are unnecessary.

The mesh convergence analysis was carried out with two concrete slabs on Winkler foundation. Five element types (C3D8, C3D8R, C3D8I, C3D20, and C3D20R) and three mesh sizes $(e=14 \mathrm{~cm}, 7 \mathrm{~cm}$, and $4.67 \mathrm{~cm})$ were adopted. The mesh size is represented by h/e (2, 4, and 6), where $h$ is the slab thickness and $e$ is the mesh size. The load transfer model was also verified on the FEA model in Figure 4. Different load transfer stiffness was considered in the verification.

The results of the convergence analysis are presented in Figure 5. It can be seen that the linear elements (C3D8 and C3D8R) hardly help to get accurate results even with very fine mesh. By simply dividing a relatively coarse mesh $(\mathrm{e}=(1 / 4) h)$, linear element $(\mathrm{C} 3 \mathrm{D} 8 \mathrm{I})$ can produce accurate results, where accuracy is close to that of the quadratic element (C3D20 and C3D20R). Consequently, the horizontal dimensions of the elements (C3D8I) used for the concrete slab are $7 \mathrm{~cm} \times 7 \mathrm{~cm}$ with four layers in the thickness direction. In Figure 5(b), the errors between the stresses calculated by the FEA model (which used C3D8I element) and the specification separately for different slab thicknesses are within 3\%. Figure 6 shows the results of the verification for the load transfer model. The LTE of each point calculated (shown in formula 1) by FEA model is approximately located on the curve proposed by Zollinger and Soares [40], which means that the joint load transfer model is reasonable.

\section{Results and Discussion}

In this study, the interaction between slabs is assessed by load transfer efficiency (LTE) for deflection or stress, as shown in

$$
\begin{aligned}
& \mathrm{LTE}_{\delta}=\frac{\delta_{U}}{\delta_{L}} \times 100 \%, \\
& \mathrm{LTE}_{\sigma}=\frac{\sigma_{U}}{\sigma_{L}} \times 100 \%,
\end{aligned}
$$

where $\mathrm{LTE}_{\delta}$ is load transfer efficiency for deflection (\%), $\mathrm{LTE}_{\sigma}$ is load transfer efficiency for stress (\%), $\delta_{L}$ is the deflection on the loaded slab $(\mathrm{m}), \delta_{U}$ is the deflection on the unloaded slab $(\mathrm{m}), \sigma_{L}$ is the tensile stress on the loaded slab $(m)$, and $\sigma_{U}$ is the tensile stress on the unloaded slab $(m)$.

3.1. Intact Pavement. To study the differences in the mechanical response of slabs under different pavement conditions, a two-slab intact pavement structure connected by a joint was modelled. A $100 \mathrm{kN}$ single-axle load (0.7 MPa in load area) was applied to the corner of the loaded slab, which was also used in Section 3.5. Figure 7 shows the stresses of the loaded slab and unloaded slab in intact pavement. It is visible that joint stiffness has a great influence on the stresses of the loaded slab and unloaded slab. Compared with the joint stiffness of $10^{3} \mathrm{q}$, the maximum tensile stress of the loaded slab with joint stiffness of $10^{-4} \mathrm{q}$ increased by $35.4 \%$, while the stress of the unloaded slab reduced to $0.004 \mathrm{MPa}$. At the same time, there appeared to be little changes in the stress of two slabs when joint stiffness was in $\left[10^{-4} \mathrm{q}, 10^{-2} \mathrm{q}\right]$ and $\left[10 \mathrm{q}, 10^{3} \mathrm{q}\right]$. The joint stiffness had a significant effect on the stress when it was in $[0.01 \mathrm{q}, 10 \mathrm{q}]$. Furthermore, the joint is similar to a hinge, while the stiffness is greater than $100 \mathrm{q}$, and the two slabs are almost completely disconnected at the joint, while the stiffness is less than $0.001 \mathrm{q}$.

The analysis showed that the existence of the base layer has a significant impact on $\mathrm{LTE}_{\delta}$. An example of the relationship between coefficient of joint stiffness $q$ and two LTEs is displayed in Figures 8 and 9 which show the relationship between $\mathrm{LTE}_{\delta}$ and $\mathrm{LTE}_{\sigma}$. The maximum value of $\mathrm{LTE}_{\sigma}$ was nearly obtained when joint stiffness is $100 \mathrm{q}$, which was $57.63 \%$. Additionally, $\mathrm{LTE}_{\sigma}$ almost reduced to 0 when joint stiffness was $0.001 \mathrm{q}$. Similar to stress, $\mathrm{LTE}_{\sigma}$ also varied drastically when joint stiffness was in [0.01q, 10q]. It can be seen that when joint stiffness was $q, \mathrm{LTE}_{\sigma}$ was $90 \%$ in Figure 8, while $\mathrm{LTE}_{\delta}$ was $40 \%$ in Figure $6 . \mathrm{LTE}_{\delta}$ calculated by considering the base course is much larger than that calculated without considering the base course, especially when the joint stiffness is small. This may be due to the fact that the deflection curve of the top surface remains continuous after the base layer is deformed, which results in a large void at the bottom of the unloaded slab. The unloaded slab can develop a larger deflection by applying smaller force, which is very different from the slab model on the Winkler foundation. This may also be the reason why the curve in Figure 9 is so steep.

3.2. Effect of Void underneath Loaded Slab. The void was only considered underneath the loaded slab and four void sizes were modelled. The vehicle load was found to have little effect on two LTEs by using four levels of vehicle load (0.6 MPa, 0.8 MPa, 1.0 MPa, and 1.2 MPa in load area). The 


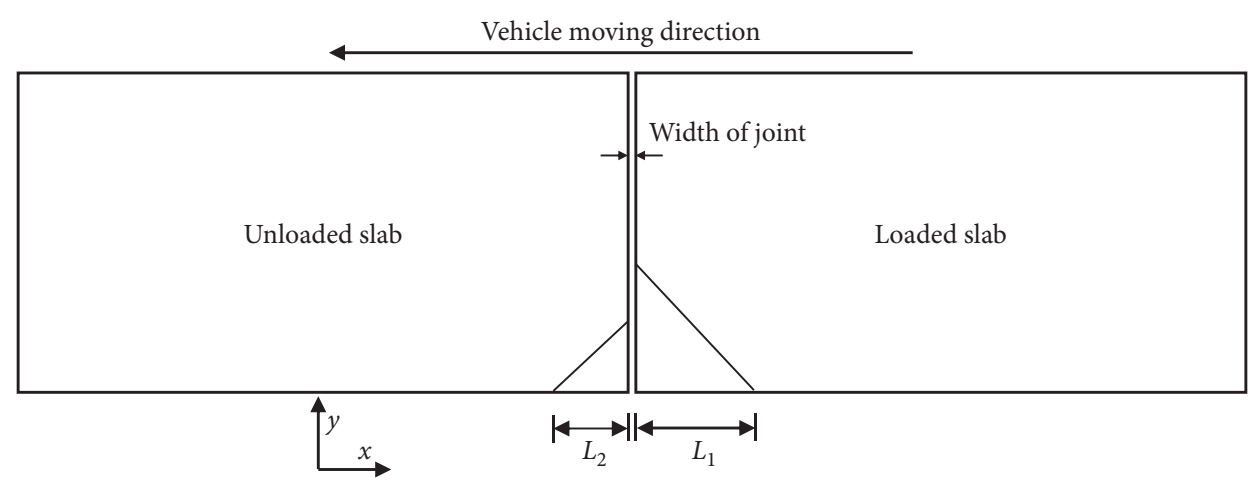

FIGURE 3: Void morphology of the FEA model.

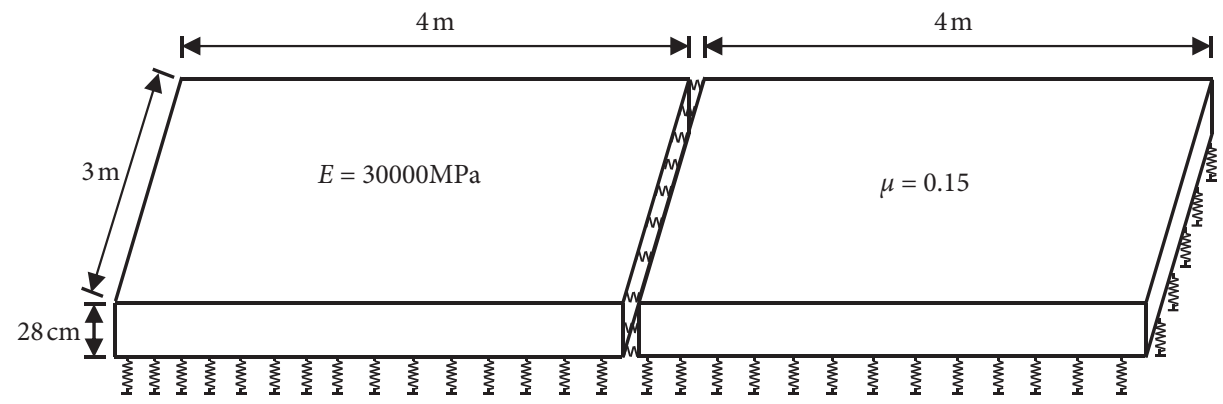

FIGURE 4: FEA model for convergence analysis.

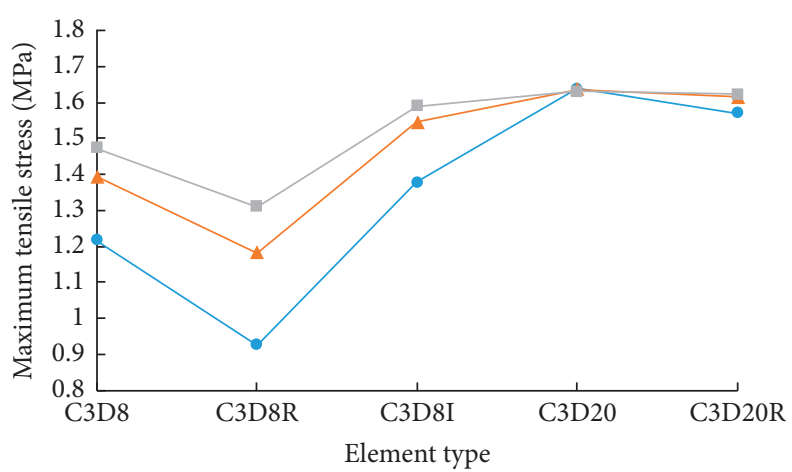

$\rightarrow \mathrm{h} / \mathrm{e}=2$

$\rightarrow \mathrm{h} / \mathrm{e}=4$

$\mathrm{h} / \mathrm{e}=6$

(a)

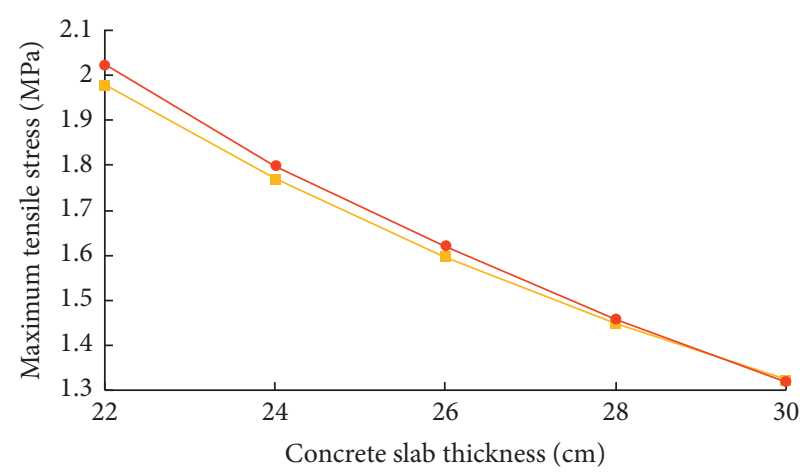

- Specification

$\rightarrow$ FEA model

FIgURE 5: The results of the convergence analysis. (a) The convergence analysis. (b) The verification of C3D8I element.

load level of $0.8 \mathrm{MPa}$ in load area was used to analyse the effect of joint stiffness on the pavement with void in Sections 3.2, 3.3, and 3.4. Figure 10 shows the relationship between void size and stress of the loaded slab in pavement with void underneath loaded slab. It is visible that the void size had little effect on the stress of the loaded slab for relatively large joint stiffness (10q and q). Specifically, the average decrements of the maximum tensile stresses with joint stiffness of $10 \mathrm{q}$ and $q$ are $3 \%$ and $5 \%$ when the void size increases from
0.3 to $1.2 \mathrm{~m}$. When the void size was $0.9 \mathrm{~m}$, the stress of the loaded slab with joint stiffness of $0.1 \mathrm{q}$ increased by $83.3 \%$ as compared to that with $0.3 \mathrm{~m}$ void and was almost equal to that with $1.2 \mathrm{~m}$ void. The stress almost linearly increases with the void size when the joint stiffness is $0.01 \mathrm{q}$. The increment of the tensile stress was $263 \%$ when the void size increased from 0.3 to $1.2 \mathrm{~m}$.

The locations of the maximum tensile stress were examined to study this interesting variation, as shown in 


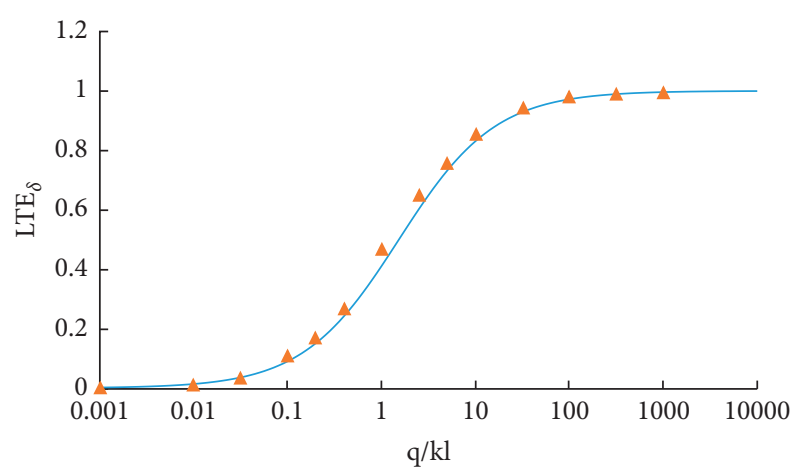

Zollinger model

$\triangle \quad$ FEA model

FIgURE 6: The verification for the load transfer model.

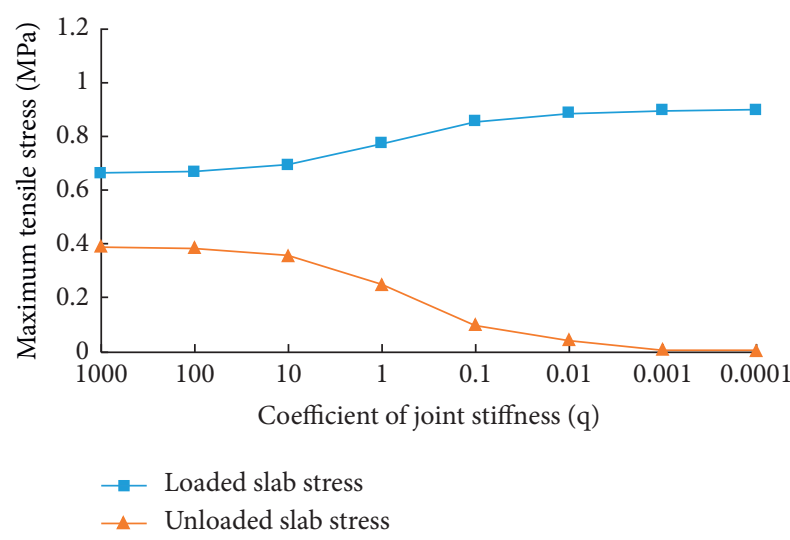

FIGURE 7: Relationship between coefficient of joint stiffness $q$ and maximum tensile stress for loaded slab and unloaded slab in intact pavement.

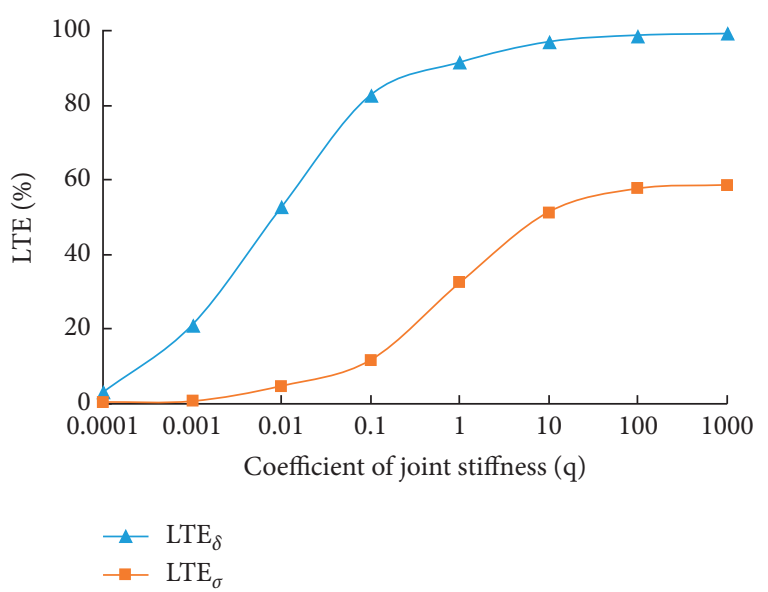

FIGURE 8: Relationship between coefficient of joint stiffness $q$ and two LTEs in intact pavement.

Figures 11 and 12. It can be seen that the maximum tensile stress in the loaded slab occurred at the slab bottom (under the inner wheel) when the joint stiffness was $10 \mathrm{q}$ and at the

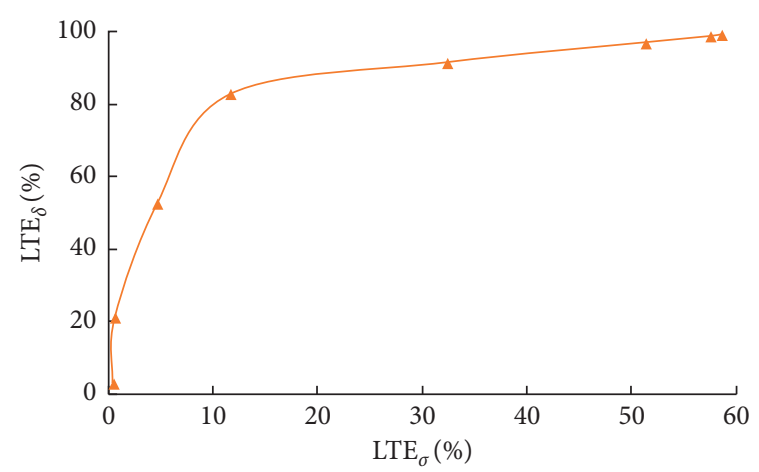

Figure 9: Relationship between $\mathrm{LTE}_{\delta}$ and $\mathrm{LTE}_{\sigma}$ in intact pavement.

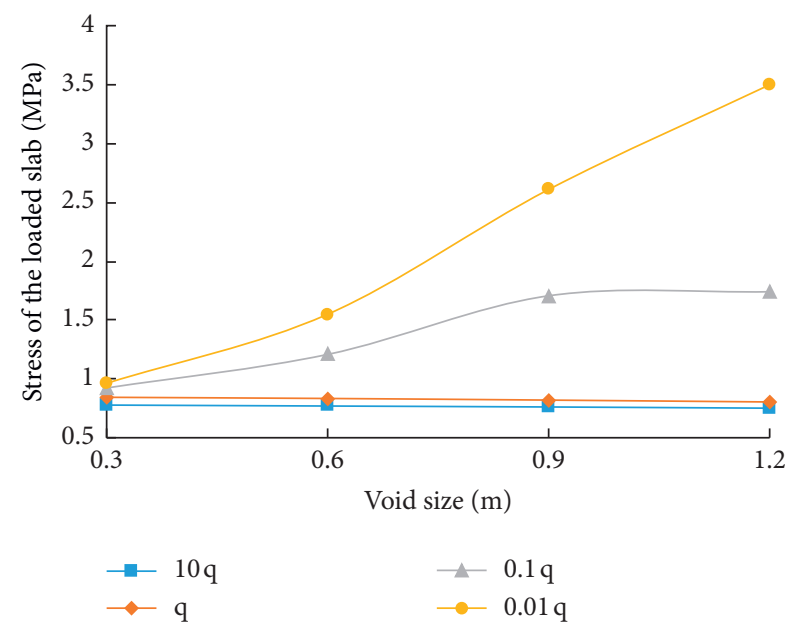

FIGURE 10: Relationship between void size and stress of the loaded slab in pavement with void underneath loaded slab.

slab top (above the edge of the void) when the joint stiffness was $0.01 q$. It is similar to the relationship between the stress and the void size of a single slab with four free edges. As the void size increases, the stress at the bottom of the slab decreases slightly, while the stress at the top increases rapidly. The location of maximum tensile stress is transferred from the bottom to the top of the loaded slab when the void size is large enough. Further analysis pointed out the location of the stress under different conditions, as shown in Table 2. Accordingly, it can be concluded that high joint stiffness can effectively reduce the effect of void on loaded slab stress. The maximum stress is more likely to occur at the loaded slab top when the joint stiffness is small.

The impacts of different void sizes on $\mathrm{LTE}_{\sigma}$ and $\mathrm{LTE}_{\delta}$ were examined. The results are presented in Figures 13 and 14. The void size has little effect on $\mathrm{LTE}_{\sigma}$ when the joint stiffnesses were $10 \mathrm{q}$ and $q$. When the void size increases from $0.3 \mathrm{~m}$ to $0.6 \mathrm{~m}, \mathrm{LTE}_{\sigma}$ with stiffness $0.1 \mathrm{q}$ increases sharply. $\mathrm{LTE}_{\sigma}$ remains at about $35 \%$ as the void size continues to increase. This may be due to a change in the location of the maximum stress. Between $0.6 \mathrm{~m}$ and $1.2 \mathrm{~m}$ of void size, $\mathrm{LTE}_{\sigma}$ with stiffness $0.01 \mathrm{q}$ increases from $4.58 \%$ to $13.29 \%$. Large 


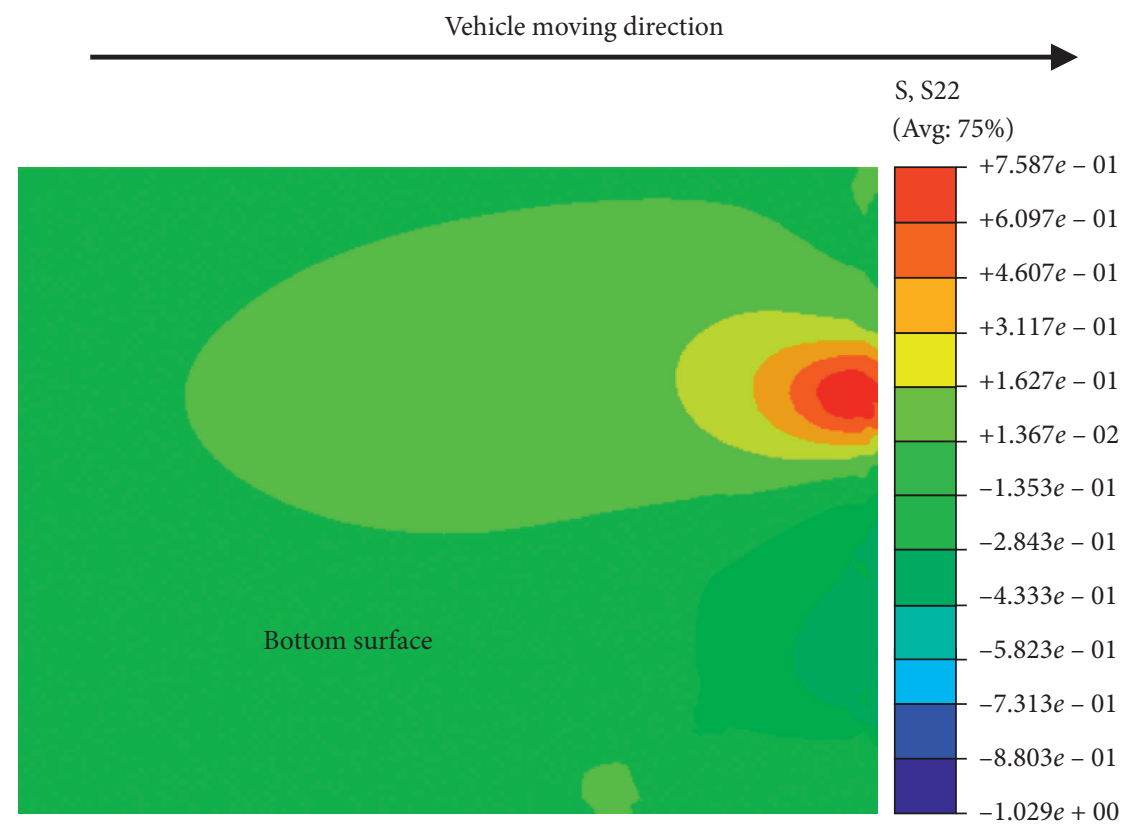

Figure 11: Tensile stress of the loaded slab with joint stiffness of $10 \mathrm{q}$ and void size of $1.2 \mathrm{~m}$ (slab bottom).

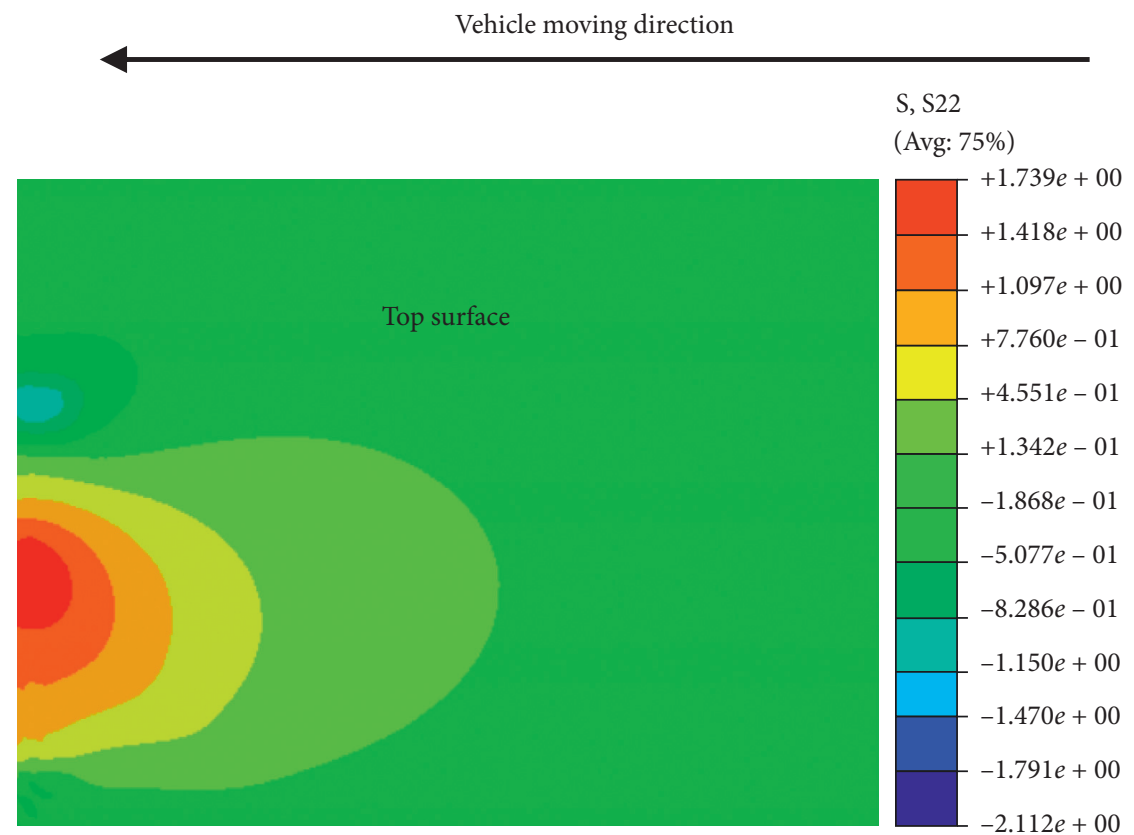

Figure 12: Tensile stress of the loaded slab with joint stiffness of $10 \mathrm{q}$ and void size of $1.2 \mathrm{~m}$ (slab top).

TABLE 2: The location of the stress under different conditions.

\begin{tabular}{lcccc}
\hline \multirow{2}{*}{ Void size $(\mathrm{m})$} & \multicolumn{4}{c}{ Joint stiffness } \\
& $10 \mathrm{q}$ & $\mathrm{q}$ & $0.1 \mathrm{q}$ & $0.01 \mathrm{q}$ \\
\hline 0.3 & 0.782 & 0.85 & 0.93 & 0.965 \\
0.6 & 0.775 & 0.84 & $1.212^{*}$ & $1.551^{*}$ \\
0.9 & 0.768 & 0.826 & $1.705^{*}$ & $2.61^{*}$ \\
1.2 & 0.759 & 0.81 & $1.739^{*}$ & $3.499^{*}$ \\
\hline
\end{tabular}

*The maximum stress occurs at the top of loaded slab. deformation can lead to the enlargement of $\mathrm{LTE}_{\sigma}$. It can be seen from Figure 14 that $\mathrm{LTE}_{\delta}$ decreases as the void size increases from $0.3 \mathrm{~m}$ to $1.2 \mathrm{~m}$. Lower joint stiffness leads to greater decrement. The decrement with stiffness $10 \mathrm{q}$ is $1.52 \%$, while it is $38.29 \%$ with stiffness $0.01 \mathrm{q}$.

3.3. Effect of Void underneath Loaded and Unloaded Slab. In addition to the loaded slab, the void underneath the unloaded slab was also considered. The areas of the two voids 


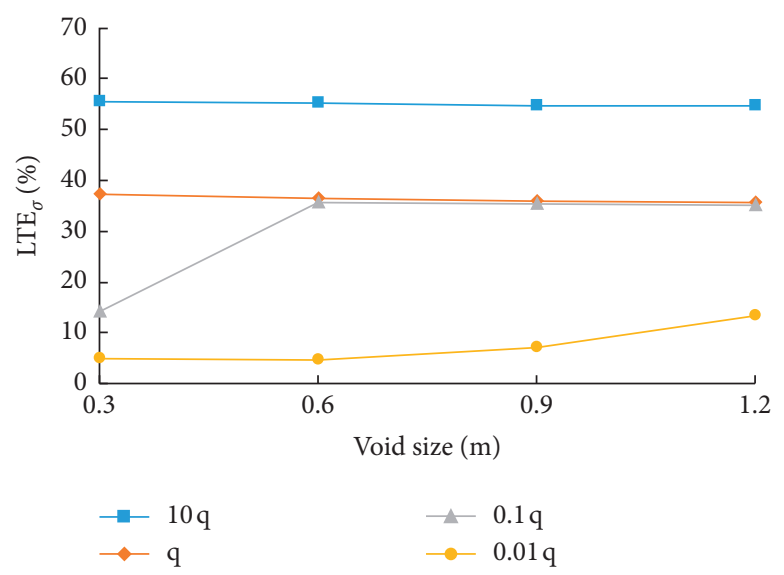

FIGURE 13: Relationship between void size and $\mathrm{LTE}_{\sigma}$ in pavement with void underneath loaded slab.

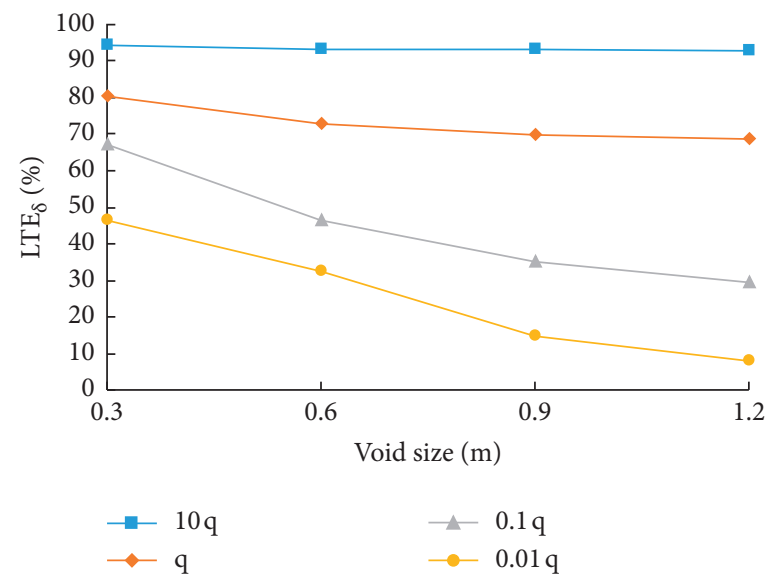

FIGURE 14: Relationship between void size and $\mathrm{LTE}_{\delta}$ in pavement with void underneath loaded slab.

are equal. It is worth noting that the slab will lose its stability when the void size reaches $1.2 \mathrm{~m}$. Consequently, three sizes of the void $(0.3 \mathrm{~m}, 0.6 \mathrm{~m}$, and $0.9 \mathrm{~m})$ were considered. The effect of void size on stress of the loaded slab is shown in Figure 15. It can be seen that the increase of the void size leads to higher stresses regardless of the joint stiffness, which is very different from the void under the loaded slab only. Lower stiffness leads to greater increment. This may be due to the fact that the unloaded slab cannot provide enough support for the loaded slab regardless of the joint stiffness. The tensile stress with different void sizes is presented in Table 3. There is no significant difference in slab stress between the four stiffnesses when the void size is $0.3 \mathrm{~m}$. This is probably because the maximum stress is located at the bottom of the slab, where there is no void. The load transfer mode is similar to the intact pavement. When the void size is $0.9 \mathrm{~m}$, the stresses with stiffnesses $10 \mathrm{q}$ and $0.01 \mathrm{q}$ increased by $79 \%$ and $182 \%$ as compared to the void size of $0.3 \mathrm{~m}$, respectively.

Figures 16 and 17 have shown the impact of different void sizes on $\mathrm{LTE}_{\sigma}$ and $\mathrm{LTE}_{\delta}$. Between the void sizes of $0.3 \mathrm{~m}$ and $0.9 \mathrm{~m}, \mathrm{LTE}_{\sigma}$ with stiffness $10 \mathrm{q}$ increased by $32 \%$ and LTE $_{\sigma}$ with stiffness $q$ increased by $31 \%$. Greater stiffness leads to higher $\mathrm{LTE}_{\sigma}$ but has little effect on increment of $\mathrm{LTE}_{\sigma}$. After a platform, $\mathrm{LTE}_{\sigma}$ with stiffness $q$ has the same growth rate as at stiffness $10 \mathrm{q}$. While $\mathrm{LTE}_{\sigma}$ with stiffness $0.01 \mathrm{q}$ decreases continuously and approaches 0 . In Figure 17, it can be seen that the void size has little effect on $\mathrm{LTE}_{\delta}$. The void underneath the unloaded slab has a significant effect on the two LTEs and the stress of the loaded slab in general.

3.4. Effect of Void Size underneath Unloaded Slab. Since the existence of void underneath the unload slab has a great influence, it is necessary to conduct research on the size of void underneath the unload slab. Two sizes of void under unloaded slab were considered, which were $1 / 3$ and $2 / 3$ of the void size under loaded slab. The tensile stress with different void sizes is presented in Table 4. For relatively smaller void sizes, the variation of void size underneath the unloaded slab has little effect on the stress in all joint stiffness, but it is significant when the void size is large. 


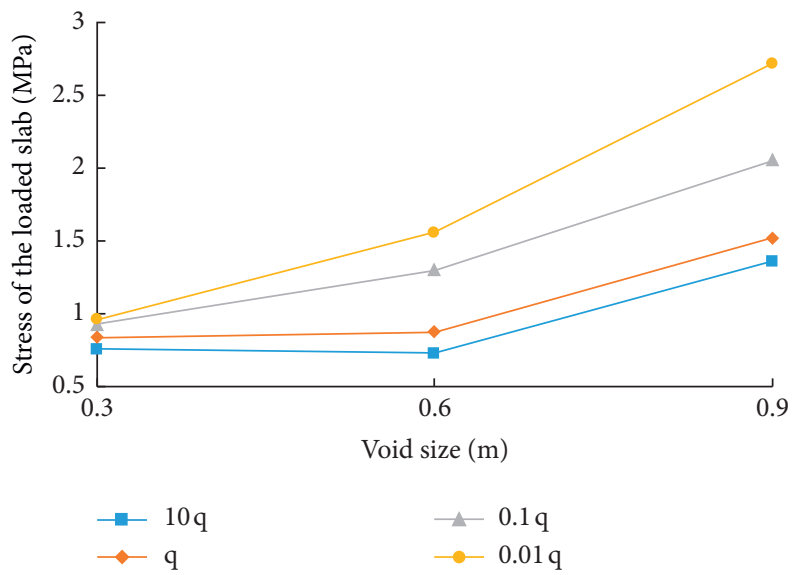

Figure 15: Effect of void size on stress of the loaded slab with void underneath loaded and unloaded slab.

TABLE 3: The location of the stress under different conditions.

\begin{tabular}{lcccc}
\hline & & \multicolumn{2}{c}{ Joint stiffness } & $0.1 \mathrm{q}$ \\
\hline 0.3 & $10 \mathrm{q}$ & $\mathrm{q}$ & 0.927 & $0.01 \mathrm{q}$ \\
0.6 & 0.761 & 0.84 & $1.301^{*}$ & 0.957 \\
0.9 & $0.732^{*}$ & $0.878^{*}$ & $2.056^{*}$ & $1.558^{*}$ \\
\hline
\end{tabular}

${ }^{*}$ The maximum stress occurs at the top of loaded slab.

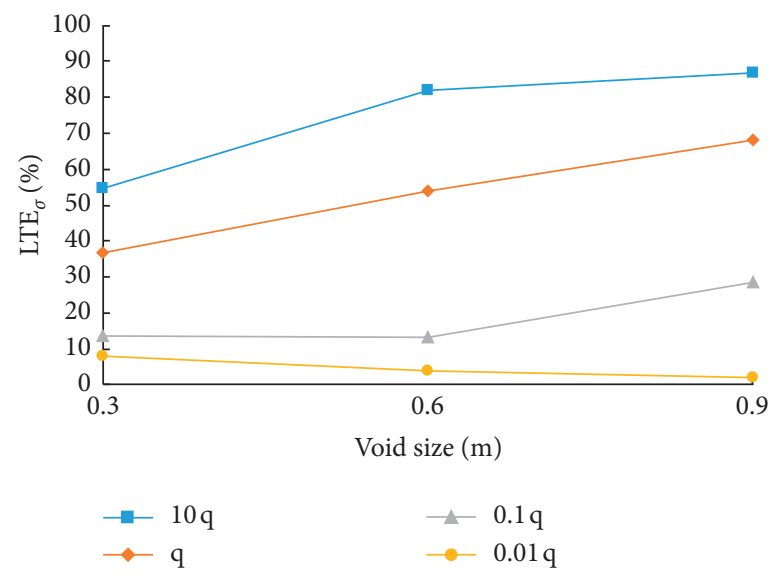

Figure 16: Relationship between void size and $\mathrm{LTE}_{\sigma}$ in pavement with void underneath loaded and unloaded slab.

When the size of the void beneath the loaded slab is $1.2 \mathrm{~m}$ and joint stiffness is $q$, the difference of the stress between the two void sizes beneath the unloaded slab is $41.4 \%$. The smaller difference is due to the lower joint stiffness. The difference is only $15.8 \%$ in the similar case with stiffness $0.1 \mathrm{q}$. Meanwhile, larger void size underneath the unloaded slab will lead to the change of the maximum stress position, such as two cases with $0.9 \mathrm{~m}$ void beneath the loaded slab and stiffness 10q. Generally, the void underneath the unloaded slab has a greater impact only when the void size and the joint stiffness are large.
3.5. Effect of Base Course Modulus. The analysis of this case is based on the model considering the void underneath the loaded slab. Five moduli of base course were modelled with two joint stiffness ( $\mathrm{q}$ and $0.01 \mathrm{q}$ ). The relationship between the stress and base course moduli for joint stiffness $q$ and $0.01 \mathrm{q}$ is shown in Figure 18. In Figure 18(a), the void size has little effect on the curve and the increment of the stress for each void size is about $9 \%$. The stress remains almost constant for the relatively smaller void size, while it has a significant change for the relatively larger void size in Figure 18(b). This interesting phenomenon can still be 


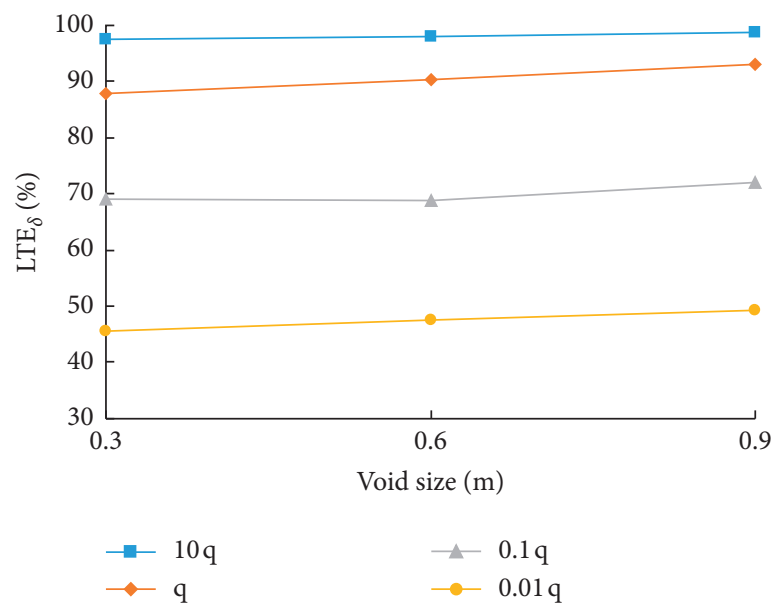

FIGURE 17: Relationship between void size and $\mathrm{LTE}_{\delta}$ in pavement with void underneath loaded and unloaded slab.

TABLE 4: The stress of loaded slab with different void sizes.

\begin{tabular}{|c|c|c|c|c|c|}
\hline \multicolumn{2}{|c|}{ Void size $(\mathrm{m})$} & \multicolumn{4}{|c|}{ Joint stiffness } \\
\hline Loaded slab & Unloaded slab & $10 \mathrm{q}$ & $\mathrm{q}$ & $0.1 \mathrm{q}$ & $0.01 \mathrm{q}$ \\
\hline \multirow{2}{*}{0.3} & 0.1 & 0.779 & 0.851 & 0.929 & 0.964 \\
\hline & 0.2 & 0.76 & 0.84 & 0.922 & 0.962 \\
\hline \multirow{2}{*}{0.6} & 0.2 & 0.746 & 0.812 & $1.246^{*}$ & $1.554^{*}$ \\
\hline & 0.4 & 0.725 & 0.802 & $1.281^{*}$ & $1.556^{*}$ \\
\hline \multirow{2}{*}{0.9} & 0.3 & 0.71 & $0.837^{*}$ & $1.766^{*}$ & $2.625^{*}$ \\
\hline & 0.6 & $0.987^{*}$ & $1.093^{*}$ & $1.869^{*}$ & $2.715^{*}$ \\
\hline \multirow{2}{*}{1.2} & 0.4 & $0.886^{*}$ & $0.957^{*}$ & $1.852^{*}$ & $3.556^{*}$ \\
\hline & 0.8 & $1.332^{*}$ & $1.353^{*}$ & $2.144^{*}$ & $3.749^{*}$ \\
\hline
\end{tabular}

*The maximum stress occurs at the top of loaded slab.

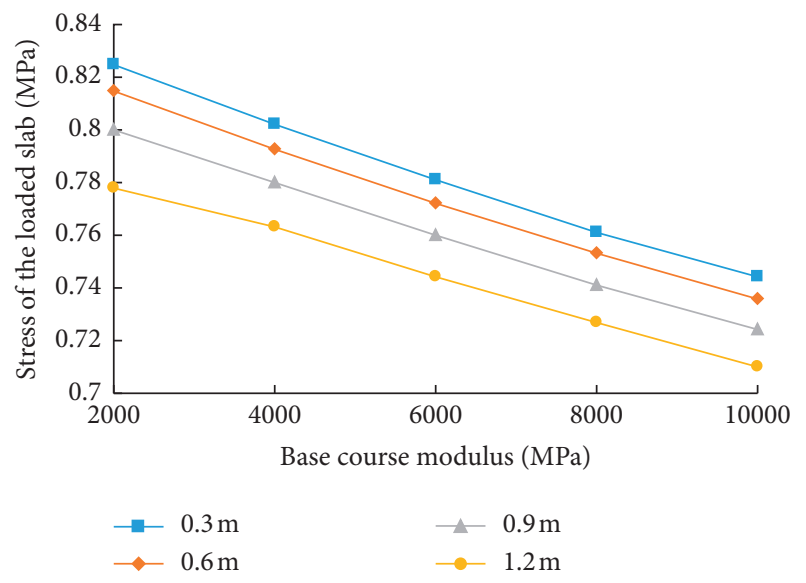

(a)

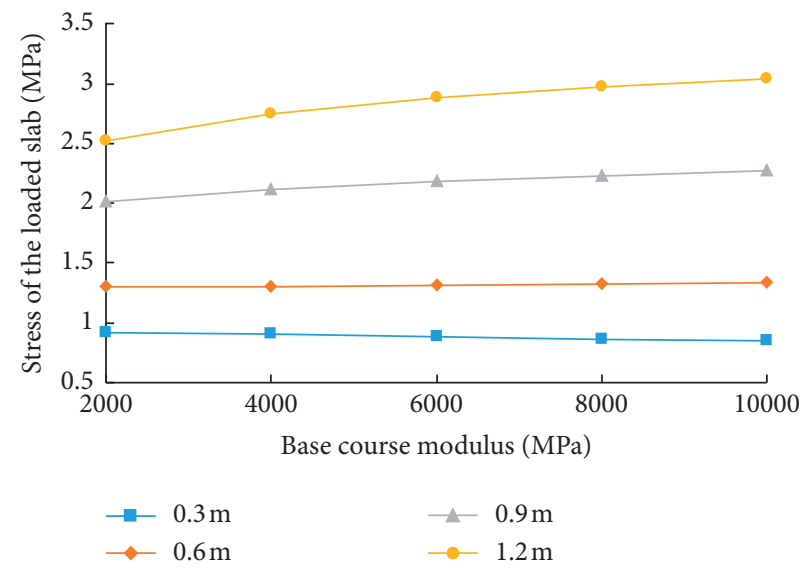

(b)

FIGURE 18: Relationship between the stress and base course modulus for joint stiffness (a) q and (b) 0.01q.

attributed to the difference in the location of the maximum stress. Table 5 presents the locations of the maximum stress under different conditions. As the base course modulus increases, the stress decreases when the maximum stress is located at the slab bottom and increases when the maximum stress is located at the slab top. Larger void size results in greater increment of the stress, as shown in Figure 19. 
TABLE 5: The location of the stress under different conditions.

\begin{tabular}{|c|c|c|c|c|c|c|}
\hline \multirow{2}{*}{ Void size $(\mathrm{m})$} & \multirow{2}{*}{ Joint stiffness } & \multicolumn{5}{|c|}{ Base course modulus ( $\mathrm{MPa})$} \\
\hline & & 2000 & 4000 & 6000 & 8000 & 10000 \\
\hline \multirow{2}{*}{0.3} & $\mathrm{q}$ & 0.825 & 0.802 & 0.781 & 0.761 & 0.744 \\
\hline & $0.01 \mathrm{q}$ & 0.922 & 0.906 & 0.886 & 0.864 & 0.844 \\
\hline \multirow{2}{*}{0.6} & & 0.815 & 0.793 & 0.772 & 0.753 & 0.736 \\
\hline & $0.01 \mathrm{q}$ & $1.299^{*}$ & $1.302^{*}$ & $1.315^{*}$ & $1.325^{*}$ & $1.34^{*}$ \\
\hline \multirow{2}{*}{0.9} & $\mathrm{q}$ & 0.8 & 0.78 & 0.76 & 0.741 & 0.724 \\
\hline & $0.01 \mathrm{q}$ & $2.012^{*}$ & $2.115^{*}$ & $2.184^{*}$ & $2.232^{*}$ & $2.269^{*}$ \\
\hline \multirow{2}{*}{1.2} & $\mathrm{q}$ & 0.778 & 0.763 & 0.744 & 0.727 & 0.71 \\
\hline & $0.01 \mathrm{q}$ & $2.518^{*}$ & $2.745^{*}$ & $2.881^{*}$ & $2.976^{*}$ & $3.046^{*}$ \\
\hline
\end{tabular}

*The maximum stress occurs at the top of loaded slab.

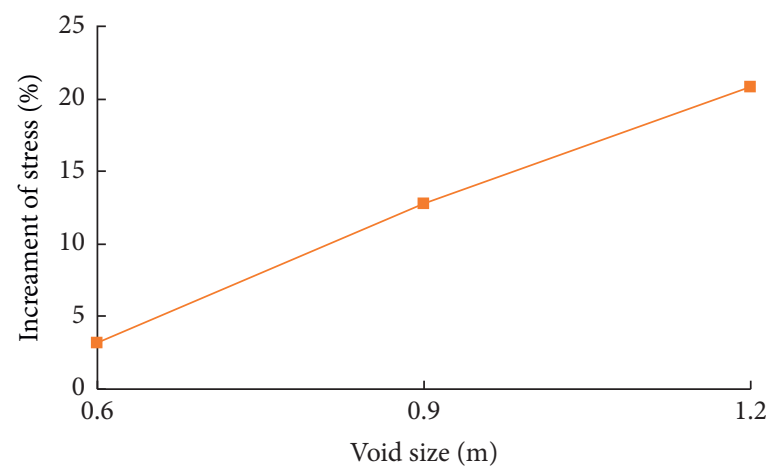

FIgURE 19: Relationship between void size and the increment of stress for stiffness $0.01 \mathrm{q}$.

\section{Conclusions}

In this paper, an FEA model with two concrete slabs was developed to study the combined effect of void and dowel looseness on the mechanical response of slabs and joint. The size of the void underneath the loaded and unloaded slab was considered. The major findings are summarized as follows:

(1) The model with slabs on Winkler foundation was validated by previous study. Meanwhile the curve of the joint stiffness changes considerably by considering the base course layer. When the joint stiffness is small, the deflection load transfer efficiency $\left(\mathrm{LTE}_{\delta}\right)$ calculated by considering the base course is much larger than that without considering the base course (i.e., slab on Winkler foundation). This may be due to the fact that the deflection curve of the top surface remains continuous after the base layer is deformed, which results in a large void at the bottom of the unloaded slab.

(2) For the model considering the void underneath the loaded slab, the void size had little effect on the stress of the loaded slab and $\mathrm{LTE}_{\sigma}$ for relatively large joint stiffness (10q and $q)$. The maximum stress occurs at the bottom of loaded slab, which is similar to that of the intact pavement. High joint stiffness can effectively reduce the effect of void on loaded slab stress.

(3) When the joint stiffness is small, the void size has a great influence on the stress of the loaded slab. The maximum stress occurs at the top of loaded slab. In this case, the concrete slab is more likely to be damaged.
(4) When void also occurs under the unloaded slab, the void size and the joint stiffness will affect the stress of the loaded slab. The smaller void size and larger joint stiffness can provide enough support for the loaded slab, so that the void size has little effect on the stress in the loaded slab. Otherwise, the increase of void size will lead to the increase of stress.

(5) The location of the maximum stress will lead to the different influence of base course modulus on stress. As the base course modulus increases, the stress decreases when the maximum stress is located at the slab bottom and increases when the maximum stress is located at the slab top. Larger void size results in greater increment of the stress.

\section{Data Availability}

The data used to support the findings of this study are included within the article.

\section{Conflicts of Interest}

The authors declare that they have no conflicts of interest.

\section{Acknowledgments}

This study was financially supported by the National Natural Science Foundation of China (no. 51778139). 


\section{References}

[1] Z. Yao, Design Theory and Procedure of Cement Concrete Pavement, China Communications Press, Beijing, China, 2003.

[2] S. R. Maitra, K. S. Reddy, and L. S. Ramachandra, "Load transfer characteristics of dowel bar system in jointed concrete pavement," Journal of Transportation Engineering, vol. 135, no. 11, pp. 813-821, 2009.

[3] L. Bronuela, H. David Lee, S. Ryu, and Y. Ho Cho, "Cantilever and pull-out tests and corresponding FEM models of various dowel bars in airport concrete pavement," Construction and Building Materials, vol. 83, pp. 181-188, 2015.

[4] Y. H. Huang, Pavement Analysis and Design, Pearson Prentice Hall, Upper Saddle River, New Jersey, 2nd ed. edition, 2004.

[5] J. A. Crovetti and M. I. Darter, "Void detection for jointed concrete pavements," Transportation Research Record, vol. 1041, pp. 59-68, 1985.

[6] W. A. Van, Rigid Pavement Pumping: (1) Subbase Erosion and (2) Economic Modelling: Informational ReportJoint Highway Research Project, West Lafayette, Indiana, 1985.

[7] American Association of State Highway and Transportation Officials (AASHTO), The AASHTO Guide for the Design of Pavement Structures, American Association of State Highway and Transportation Officials (AASHTO), Washington, DC, 4th ed edition, 2011.

[8] K. Alland, J. M. Kevin, and J. Brigham, "Statistical model to detect voids for curled or warped concrete pavements," Transportation Research Record: Journal of the Transportation Research Board, vol. 2639, no. 1, pp. 28-38, 2017.

[9] M. A. Bhatti, J. A. Barlow, and J. W. Stoner, "Modeling damage to rigid pavements caused by subgrade pumping," Journal of Transportation Engineering, vol. 122, pp. 1-12, 1996.

[10] J. M. Ruiz, R. O. Rasmussen, and G. K. Chang, Computerbased Guidelines for Concrete Pavements. Volume II: Design and Construction Guidelines and HIPERPAV II User's Manual, Transtec Group, Austin, TX, USA, 2005.

[11] Y. Q. Xue, Research on Fatigue Damage Mechanism and Maintenance Countermeasure for Cement Concrete Pavement, Southeast University, Nanjing, China, 2012.

[12] A. J. VanWijk, J. Larralde, C. W. Lovell, and W. F. Chen, "Pumping prediction model for highway concrete pavements," Journal of Transportation Engineering, vol. 115, 1989.

[13] Y. C. Suh, K. Hankins, and B. F. McCullough, Early-age Behavior of Continuously Reinforced Concrete Pavement and Calibration of the Failure Prediction Model in the CRCP-7 Program (Report No. 1244-3), Center for Transportation Research, Austin, TX, USA, 1992.

[14] American Concrete Pavement Association, Slab Stabilization Guidelines for Concrete Pavements, Technical Bulletin TB018P, Skokie, IL, USA, 1994.

[15] H. M. Westergaard, "Analysis of stresses in concrete pavements due to variations of temperature," Proc Highway Res Board, vol. 6, pp. 201-215, 1927.

[16] J. Q. Chen, H. Wang, and P. Y. Xie, "Finite element modeling of mechanical responses of concrete pavement with partial depth repair," Construction Building Materials, vol. 240, 2020.

[17] A. Rezaei-Tarahomi, O. Kaya, H. Ceylan, S. Kim, K. Gopalakrishnan, and D. R. Brill, "Development of rapid three-dimensional finite-element based rigid airfield pavement foundation response and moduli prediction models," Transportation Geotechnics, vol. 13, pp. 81-91, 2017.

[18] K. Kim and S. Chun, "Evaluation of internally cured concrete pavement using environmental responses and critical stress analysis," International Journal of Concrete Structures and Materials, vol. 9, no. 4, pp. 463-473, 2015.

[19] K. Kim, S. Chun, S. Han, and M. Tia, "Effect of dowel bar arrangements on performance of jointed plain concrete pavement (JPCP)," International Journal of Concrete Structures, vol. 12, pp. 519-529, 2018.

[20] T. W. Aure and A. M. Ioannides, "Fracture analysis of aggregate interlock jointed slabs-on-grade," Construction and Building Materials, vol. 77, pp. 340-348, 2015.

[21] M. Y. Darestani, D. P. Thambiratnam, A. Nataatmadja, and D. Baweja, "Structural response of concrete pavements under moving truck loads," Journal of Transportation Engineering, vol. 133, no. 12, pp. 670-676, 2007.

[22] J. Ling, F. Wei, H. Zhao, Y. Tian, B. Han, and Z. a. Chen, "Analysis of airfield composite pavement responses using fullscale accelerated pavement testing and finite element method," Construction and Building Materials, vol. 212, pp. 596-606, 2019.

[23] A. Sarkar and R. Norouzi, "Evaluating curling stress of continuous reinforced concrete pavement," Aci Structural Journal, vol. 117, pp. 53-62, 2020.

[24] S. Ali, S. Fawzia, D. Thambiratnam, X. Liu, and A. M. Remennikov, "Performance of protective concrete runway pavement under aircraft impact loading," Structure and Infrastructure Engineering, vol. 16, pp. 1-13, 2020.

[25] H. Gu, X. Jiang, Z. Li, K. Yao, and Y. Qiu, "Comparisons of two typical specialized finite element programs for mechanical analysis of cement concrete pavement," Mathematical Problems in Engineering, vol. 2019, Article ID 9178626, 11 pages, 2019.

[26] S. Yang, Y. Zhang, O. Kaya, H. Ceylan, and S. Kim, "Investigation of longitudinal cracking in widened concrete pavements," The Baltic Journal of Road and Bridge Engineering, vol. 15, no. 1, pp. 211-231, 2020.

[27] M. B. Bayrak and H. Ceylan, "Neural network-based approach for analysis of rigid pavement systems using deflection data," Transportation Research Record: Journal of the Transportation Research Board, vol. 2068, no. 1, pp. 61-70, 2008.

[28] N. Buch and D. G. Zollinger, "Development of dowel looseness prediction model for jointed concrete pavements," Transportation Research Record, Transportation Research Board, Washington, D.C., vol. 1525, pp. 21-27, 1996.

[29] H. Guo, J. A. Sherwood, and M. B. Snyder, "Component dowel-bar model for load-transfer systems in PCC pavements," Journal of Transportation Engineering, vol. 121, no. 3, pp. 289-298, 1995.

[30] J. Grosek, A. Zuzulova, and I. Brezina, "Effectiveness of dowels in concrete pavement," Materials, vol. 12, no. 10, p. 1669, 2019.

[31] P. Mackiewicz, "Analysis of stresses in concrete pavement under a dowel according to its diameter and load transfer efficiency," Canadian Journal of Civil Engineering, vol. 42, no. 11, pp. 845-853, 2015.

[32] T. W. Aure and A. M. Ioannides, "Curling effects on concrete slab-on-grade fracture," Materials and Structures, vol. 49, no. 8, pp. 2991-3004, 2016.

[33] L. Bronuela, H. "David" Lee, S. Ryu, and Y. Ho Cho, "Cantilever and pull-out tests and corresponding FEM models of various dowel bars in airport concrete pavement," Construction and Building Materials, vol. 83, pp. 181-188, 2015.

[34] Y. M. Zhou, Z. M. Tan, and J. Zhao, "Loading stress in cement concrete pavement structure with base widening," Journal of Tongji University, vol. 35, p. 10, 2007. 
[35] J.-H. Jeong, J.-Y. Park, J.-S. Lim, and S.-H. Kim, “Testing and modelling of friction characteristics between concrete slab and subbase layers," Road Materials and Pavement Design, vol. 15, no. 1, pp. 114-130, 2013.

[36] T. Nishizawa, T. Ozeki, K. Katoh, and K. Matsui, "Finite element model analysis of thermal stresses of thick airport concrete pavement slabs," Transportation Research Record: Journal of the Transportation Research Board, vol. 2095, no. 1, pp. 3-12, 2009.

[37] Z. F. Zhou, Finite Element Analysis of the Load Transfer Efficiency of Joints of Airport Rigid Pavement, Tongji University, Shanghai, China, 2009.

[38] Y. Huang, J. Yuan, and Y. Tan, "Identification of void beneath airport cement concrete pavement and its influecce," Journal of Tongji University, vol. 40, no. 6, 2012.

[39] H. J. Oh, S.-M. Kim, W. Chung, Y. H. Lee, and Y. K. Cho, "Effect of joint type on rigid airfield pavement behavior," KSCE Journal of Civil Engineering, vol. 18, no. 5, pp. 13891396, 2014.

[40] D. G. Zollinger and J. Soares, Performance of Continuously Reinforced Concrete Pavements: Volume VII: Summary, Final Repor. Federal Highway Administration. FHWA-RD-98102, PCS/Law Engineering, Washington DC, USA, 1999. 